\title{
Distinct Metal Ion Requirements for the Phosphomonoesterase and Phosphodiesterase Activities of Calf Intestinal Alkaline Phosphatase
}

\author{
Adedoyin Igunnu ${ }^{1}$, Dunsin S. Osalaye ${ }^{2}$, Olufunso O. Olorunsogo ${ }^{2}$, Sylvia O. Malomo $^{* 1}$ and \\ Femi J. Olorunniji*,1,3 \\ ${ }^{I}$ Department of Biochemistry, Faculty of Science, University of Ilorin, Ilorin, Nigeria \\ ${ }^{2}$ Department of Biochemistry, College of Basic Medical Sciences, University of Ibadan, Ibadan, Nigeria \\ ${ }^{3}$ Institute of Molecular Cell and Systems Biology, University of Glasgow, Bower Building, Glasgow G12 8QQ, Scotland, \\ $U K$
}

\begin{abstract}
The roles of $\mathrm{Mg}^{2+}$ and $\mathrm{Zn}^{2+}$ ions in promoting phosphoryl transfer catalysed by alkaline phosphatase are yet to be fully characterised. We investigated the divalent metal ion requirements for the monoesterase and diesterase activities of calf intestinal alkaline phosphatase. The synergistic effect of $\mathrm{Mg}^{2+}$ and $\mathrm{Zn}^{2+}$ in promoting the hydrolysis of paranitrophenyl phosphate (monoesterase reaction) by alkaline phosphatase is not observed in the hydrolysis of the diesterase substrate, bis-para-nitrophenyl phosphate. Indeed, the diesterase reaction is inhibited by concentrations of $\mathrm{Mg}^{2+}$ that were optimal for the monoesterase reaction. This study reveals that the substrate specificities of alkaline phosphatases and related bimetalloenzymes are subject to regulation by changes in the nature and availability of cofactors, and the different cofactor requirements of the monoesterase and diesterase reactions of mammalian alkaline phosphatases could have significance for the biological functions of the enzymes.
\end{abstract}

Keywords: Alkaline phosphatase, phosphodiester hydrolysis, metal ion cofactors.

\section{INTRODUCTION}

Alkaline phosphatases (APs) are dimeric metalloenzymes (Fig. 1) that catalyse the hydrolytic transfer of phosphate to water or its transphosphorylation to amino alcohols, but when separated the monomeric subunits fail to display enzyme activity [1]. Each monomeric subunit of AP contains three divalent cations (two $\mathrm{Zn}^{2+}$ and one $\mathrm{Mg}^{2+}$ ) and a serine residue in the active site [2]. Previous studies on E. coli AP (ECAP) have shown that the two zinc ions are directly involved in catalysis (Fig. 2A) [2-4]. The two zinc ions are well positioned to activate the serine and water for nucleophilic attacks and they are involved in holding the phosphate moiety of substrate [2]. The $\mathrm{Zn}^{2+}$ ion at the first metal ion binding site (M1 site) is required for catalysis and plays an important role in binding both the substrate and the phosphate released upon hydrolysis (Fig. 2A). The second $\mathrm{Zn}^{2+}$ ion interacts with the hydroxyl group of the active site serine to stabilize the deprotonated form of the residue required for the nucleophilic attack on the phosphate [2]. Recent evidence suggests that the $\mathrm{Mg}^{2+}$ ion in the active site stabilizes the transferred phosphoryl group via a water molecule (Fig. 2A), and functions via a mechanism different from the two $\mathrm{Zn}^{2+}$ ions at the bimetallocentre [5].

*Address correspondence to these authors at the Institute of Molecular Cell and Systems Biology, University of Glasgow, Bower Building, Glasgow G12 8QQ, Scotland, UK; Tel: +441413303331;

E-mail: Femi.Olorunniji@glasgow.ac.uk

Department of Biochemistry, Faculty of Science, University of Ilorin, Ilorin, Nigeria; Tel: +2348033736997; E-mail: somalomo@unilorin.edu.ng
APs have been classified into a superfamily of phospho/sulfo-coordinating enzymes catalyzing the hydrolysis of phosphate monoesters, diesters, triesters, and sulfate esters [6]. The phosphodiesterase activity of AP has been demonstrated in the enzyme from rat osseous plate [7] and $E$. coli [6]. Mutational analysis suggests that common active site features contribute to hydrolysis of both phosphate monoesters and phosphate diesters. However mutation of the active site arginine to serine, R166S, decreases the phosphomonoesterase activity but not the diesterase activity, suggesting that interaction of this arginine with the nonbridging oxygen(s) of the phosphate monoester substrate is responsible for the preferential hydrolysis of phosphate monoesters [6].

Two-metal ion catalysis is a common feature of enzymes that catalyze phosphoryl transfer reactions including the hydrolysis of phosphate monoesters, diesters and triesters $[8$, 9]. The active sites of members of the alkaline phosphatase superfamily share several structural features underscored by the two-metal catalytic centre. Comparative analyses of the monoesterase and diesterase activities of APs are providing new insights into their catalytic mechanism $[5,7,10]$.

The structural similarity shared by the active sites of related mono- and diesterases raises the possibility that any bimetallo active site might be able to catalyze these different classes of reactions. However, the partial negative charge on a phosphoryl oxygen atom of the phosphate monoester dianion is lost upon conversion to a diester monoanion, and the steric bulk of the added esterifying group of the diester could result in steric clashes within the active site [6]. 

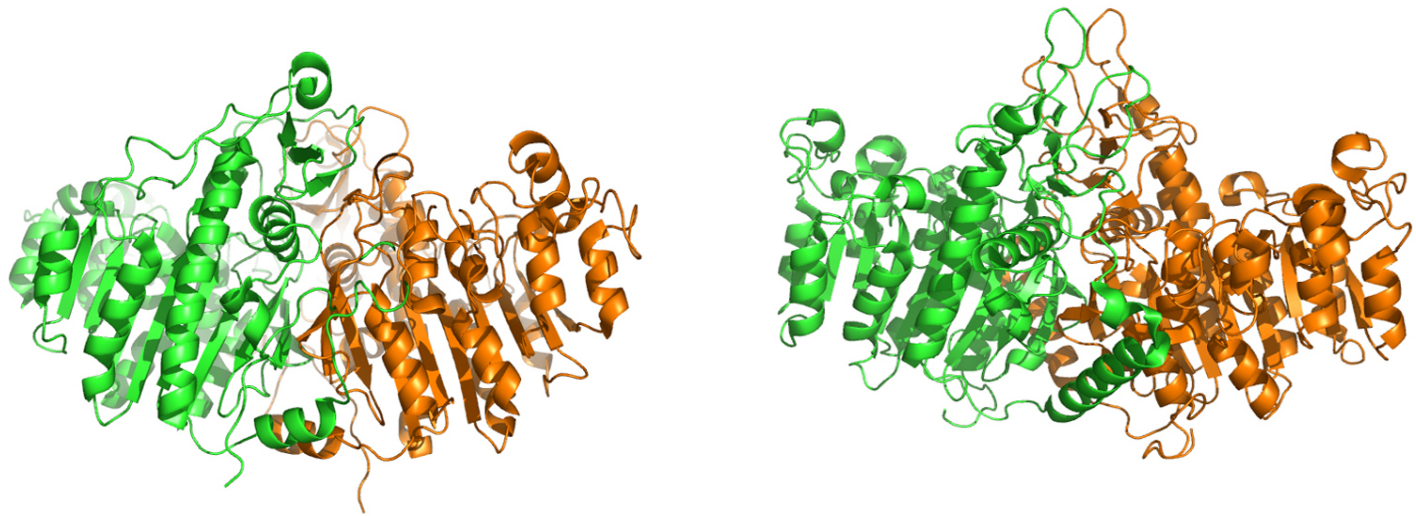

Fig. (1). Crystal structure of alkaline phosphatase from E. coli (A) and human placenta (B) highlighting the structural similarity between bacterial and mammalian forms of the enzyme. Monomer subunits are coloured differently to highlight the dimeric nature of the enzymes. Coordinates of the structures were downloaded from http://www.rcsb.org/pdb and the images were produced using PyMOL [22]. The pdb accession numbers are ALK1 (E. coli alkaline phosphatase) and 1EW2 (human placental alkaline phosphatase).

A

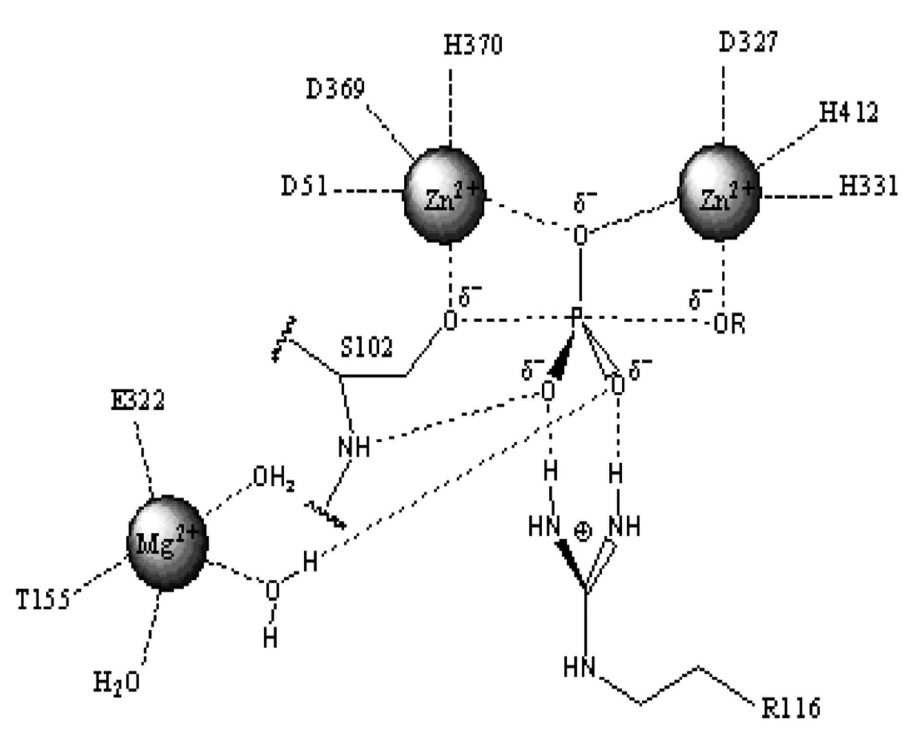

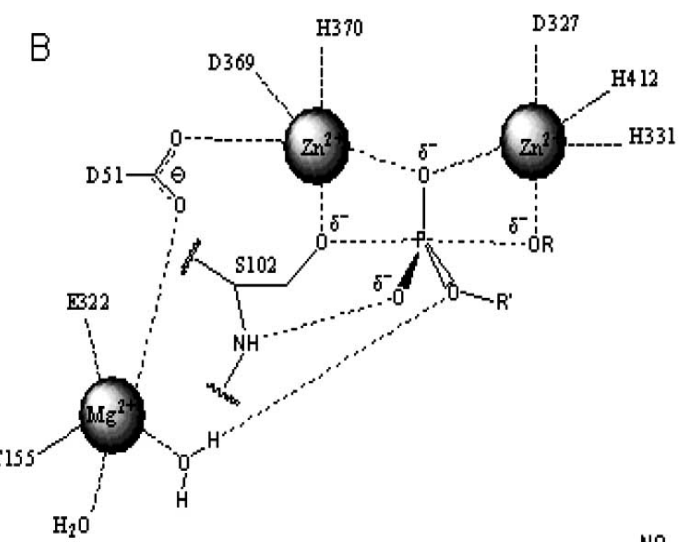

C

PNPP<smiles>O=[N+]([O-])c1ccc(OP(=O)([O-])[O-])cc1</smiles>

his-pkPP

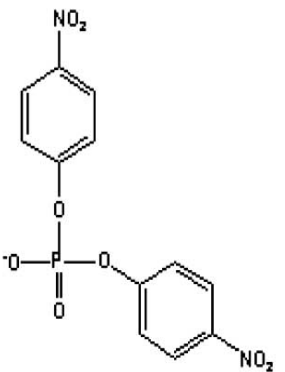

Fig. (2). Structure of the active site and proposed reaction mechanism of alkaline phosphatase. (A). Schematic illustration of the active site and reaction mechanism of $E$. coli alkaline phosphatase. The bimetallocentre is occupied by the two $\mathrm{Zn}^{2+}$ ions, and $\mathrm{Mg}^{2+}$ ion at the third site is shown interacting with a non-bridging oxygen via a water molecule. (B). Proposed orientation of the R' group of the diester substrate in the active site. The $\mathrm{R}^{\prime}$ group is oriented away from the $\mathrm{Mg}^{2+}$ site suggesting that hydrolysis of the diester substrate is less dependent on rate enhancement contribution from $\mathrm{Mg}^{2+}$. These figures are adapted from Zalatan et al., [5]. (C). Chemical structures of para-nitrophenyl phosphate (pNPP) and bis-para-nitrophenylphosphate (bis-pNPP) used as substrates for the monoesterase and diesterase activities of calf intestinal alkaline phosphatase.

Mammalian APs are found in several tissues including the intestine, kidney, liver and bone. Mammalian alkaline phosphatases perform a variety of functions including bone mineralization and fat absorption in the intestine, as well as vents in early embryogenesis [11]. These enzymes show structural similarity to ECAP (Fig. 1), and strong sequence conservation is seen in regions where the catalytic residues are located [12]. The APs from these sources act upon different phosphate monoesters and diesters. Hence, the mechanistic details of how mammalian APs deal with monoand diester substrates is important to our understanding of the biological functions of the enzymes. 
Divalent metal ions (such as $\mathrm{Mg}^{2+}$ and $\mathrm{Zn}^{2+}$ ) have both activating and inhibitory effects on mammalian alkaline phosphatase $[1,13,14]$. In an earlier report, we showed that optimal concentrations of both $\mathrm{Mg}^{2+}$ and $\mathrm{Zn}^{2+}$ were required for the tissue non-specific AP (TNAP) to catalyze the hydrolysis of the monoester substrate para-nitrophenyl phosphate [15]. Here, we investigate the effects of cofactor interactions on monoesterase and diesterase activities of calf intestinal AP (CIAP) with a view to gaining further insight into the interaction between the metal ions in AP catalysis.

\section{MATERIALS AND METHODOLOGY}

\section{Reagents, Chemicals, and Enzyme}

Alkaline phosphatase substrates, the sodium salts of paranitrophenylphosphate (pNPP) and bis-para-nitrophenyl-

A

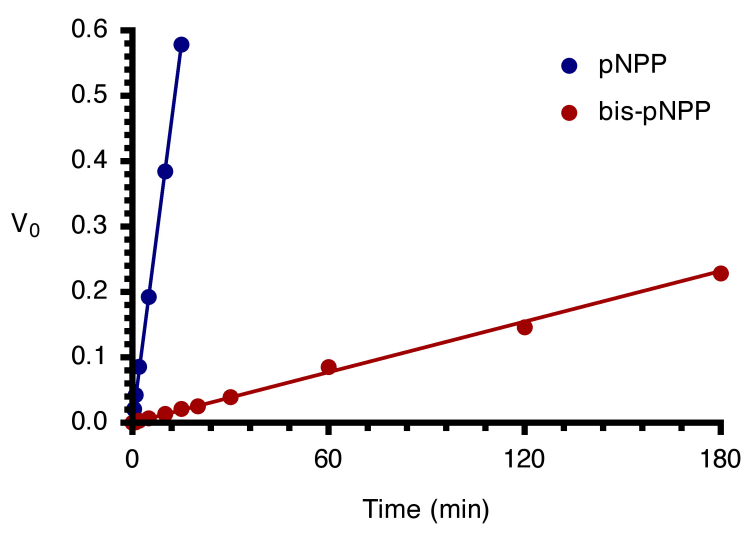

phosphate (bis-pNPP), were obtained from Sigma-Aldrich, UK. Magnesium chloride $\left(\mathrm{MgCl}_{2}\right)$ and zinc chloride $\left(\mathrm{ZnCl}_{2}\right)$ were obtained from Fisher Scientific, UK. Homogenous CIAP was obtained from New England Biolabs, UK.

\section{AP-Catalyzed Hydrolysis of pNPP and Bis-pNPP}

Phosphomonoesterase and diesterase activities of CIAP were measured by the rate of hydrolysis of pNPP and bispNPP (Fig. 2C) respectively in the presence of the divalent metal ions $\mathrm{Zn}^{2+}$ and $\mathrm{Mg}^{2+}$ [7] at $37^{\circ} \mathrm{C}$ in $25 \mathrm{mM}$ Tris- $\mathrm{HCl}$ $(\mathrm{pH}$ 8.5). Details of each experiment are described in the Figure Legends. Reaction mixtures containing CIAP and buffers in the presence of the appropriate metal ions were incubated at $37{ }^{\circ} \mathrm{C}$ for 10 minutes. Reactions were initiated by the addition of the appropriate concentration of the substrate. The absorbance was read at $410 \mathrm{~nm}$ against a

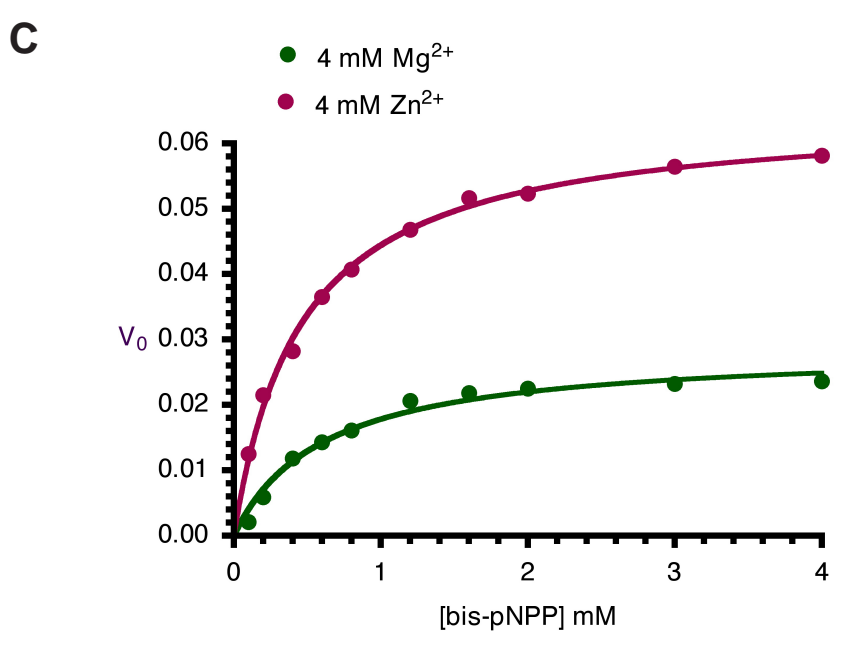

Fig. (3). Kinetics of monoesterase and diesterase activities of CIAP. (A). Time course of hydrolysis of pNPP and bis-pNPP. Reaction mixtures $(200 \mu \mathrm{l})$ containing $25 \mathrm{mM}$ Tris- $\mathrm{HCl}(\mathrm{pH} 8.5), 2.5 \mathrm{mM}$ p-nitrophenyl phosphate (or bis-p-nitrophenyl phosphate), $100 \mu \mathrm{M} \mathrm{ZnCl} 2,1$ $\mathrm{mM} \mathrm{MgCl} 2$, and $10 \mu \mathrm{M} \mathrm{CIAP}$ were incubated at $37{ }^{\circ} \mathrm{C}$ for the indicated time. Reactions were initiated by the addition of the substrate to the reaction mixture and stopped by the addition of $1.0 \mathrm{ml} 0.5 \mathrm{M} \mathrm{NaOH}$. Activities are expressed as change in $\mathrm{A}_{410}$ per minute for phosphomonoesterase activity and change in $\mathrm{A}_{410}$ per hour for the phosphodiesterase activity. (B) Effects of $\mathrm{Zn}^{2+}$ and $\mathrm{Mg}^{2+}$ on kinetics of CIAP-catalyzed hydrolysis of pNPP. The initial rates of hydrolysis of increasing concentrations of pNPP by $10 \mu \mathrm{M}$ CIAP at $37{ }^{0} \mathrm{C}$ in the presence of $4 \mathrm{mM} \mathrm{Zn}^{2+}$ or $4 \mathrm{mM} \mathrm{Mg}^{2+}$ were determined. The data were fitted to the Michaelis-Menten curve using GraphPad Prism curvefitting software. The concentrations of pNPP used were $0.025,0.05,0.1,0.15,0.2,0.3,0.4,0.5,0.75$, and $1.0 \mathrm{mM}$. (C) Effects of $\mathrm{Zn}^{2+}$ and $\mathrm{Mg}^{2+}$ on kinetics of CIAP-catalyzed hydrolysis of bis-pNPP. Reactions and data analysis were carried out as described in (B). The concentrations of bis-pNPP used were $0.1,0.2,0.4,0.6,0.8,1.2,1.6,2.0,3.0$, and $4.0 \mathrm{mM}$. 
blank of the buffered substrate. Spectrophotometric readings were taking in a Perkin Elmer Lambda 45 UV/VIS instrument and a Spectronic 21 spectrophotometer. All measurements of reaction rate were performed in triplicates.

\section{RESULTS}

Earlier studies on Escherichia coli AP (ECAP) showed that the enzyme is less efficient at hydrolyzing phosphodiester substrates than phosphomonoesters [6]. Here, we compared the rates of hydrolysis of pNPP and bis-pNPP by CIAP using a simple time-course analysis. Both reactions were studied under identical conditions of $2.5 \mathrm{mM}$ substrate concentration. This concentration is sufficient to saturate 10 $\mu \mathrm{M}$ CIAP used in these reactions $[14,15]$. Hydrolysis of pNPP in the monoesterase reaction was monitored spectrophotometrically over 15 minutes, while the slower phosphodiester hydrolysis of bis-pNPP was followed for 180 minutes. The rates of both reactions were linear over the time ranges studied. The monoesterase activity $\left(0.0383 \mathrm{~min}^{-1}\right)$ was 30 times faster than the diesterase activity $\left(0.0013 \mathrm{~min}^{-1}\right)$ of CIAP under these conditions (Fig. 3A). These results show that the CIAP active site is better adapted to deal with monoesters than phosphodiester substrates, and are in agreement with earlier studies on related members of the alkaline phosphatase superfamily $[6,16]$.

In order to characterize the metal ion preference of CIAP for the two activities, we compared the effects of $\mathrm{Zn}^{2+}$ and $\mathrm{Mg}^{2+}$ on the hydrolysis of pNPP and bis-pNPP. CIAP was incubated with $4 \mathrm{mM} \mathrm{Mg}{ }^{2+}$ or $\mathrm{Zn}^{2+}$ at $37^{\circ} \mathrm{C}$ for 10 minutes to ensure binding to the metal ion sites of the enzyme [15]. The cofactor-saturated CIAP were added to reaction mixtures containing increasing concentrations of pNPP and bis-pNPP. Initial rates were determined over linear ranges similar to those shown in Fig. (3A), and the values were plotted as Michaelis-Menten curves in Figs. (3B and 3C). The results show that the two metal ions manifest opposite effects on monoesterase and diesterase activities of CIAP. Kinetic constants calculated from the pNPP reaction show that $\mathrm{Mg}^{2+}$ $\left(\mathrm{V}_{\max } 0.493 \mathrm{~min}^{-1}, \mathrm{~K}_{\mathrm{m}} 0.239 \mathrm{mM}, \mathrm{K}_{0} 2.062\right)$ was a better activator than $\mathrm{Zn}^{2+}\left(\mathrm{V}_{\max } 0.169 \mathrm{~min}^{-1}, \mathrm{~K}_{\mathrm{m}} 0.201 \mathrm{mM}, \mathrm{K}_{0}\right.$

A

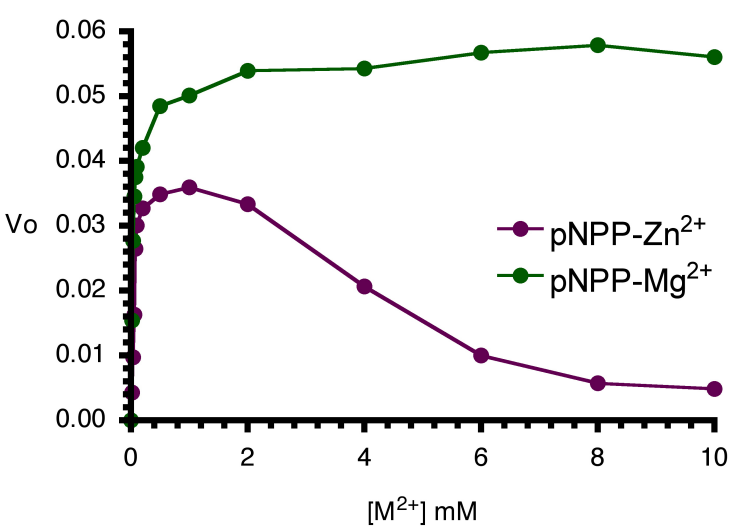

0.841). In contrast, $\mathrm{Zn}^{2+}\left(\mathrm{V}_{\max } 0.065 \mathrm{~min}^{-1}, \mathrm{~K}_{\mathrm{m}} 0.459 \mathrm{mM}, \mathrm{K}_{0}\right.$ $0.141)$ was preferred to $\mathrm{Mg}^{2+}\left(\mathrm{V}_{\max } 0.029 \mathrm{~min}^{-1}, \mathrm{~K}_{\mathrm{m}} 0.607\right.$ $\mathrm{mM}, \mathrm{K}_{0} 0.047$ ) in the hydrolysis of bis-pNPP by CIAP.

Next, we examined the effects of increasing cofactor concentrations $\left(\mathrm{Zn}^{2+}\right.$ and $\left.\mathrm{Mg}^{2+}\right)$ on the monoesterase and diesterase activities of CIAP. Aliquots of CIAP were incubated with 0 to $10 \mathrm{mM} \mathrm{Mg}{ }^{2+}$ and/or $\mathrm{Zn}^{2+}$ at $37{ }^{\circ} \mathrm{C}$ for 10 minutes as described earlier. The effect of $\mathrm{Zn}^{2+}$ was biphasic as the activation effect peaked, and increasing concentration resulted in a steady decrease in activity. In contrast, $\mathrm{Mg}^{2+}$ at equivalent concentration led to continued activity of the monoesterase reaction. The effects of $\mathrm{Mg}^{2+}$ and $\mathrm{Zn}^{2+}$ on the diesterase activity of CIAP (Fig. 4B) were different from the pattern seen in the monoesterase reaction (Fig. 4B). $\mathrm{Zn}^{2+}$ was a better activator of bis-pNPP hydrolysis, and only marginal stimulation of activity resulted from pre-incubation of the enzyme with $\mathrm{Mg}^{2+}$. Higher concentration $(10 \mathrm{mM})$ of $\mathrm{Zn}^{2+}$ did not inhibit bis-pNPP (Fig. 4B) hydrolysis in contrast to the inhibition caused by $\mathrm{Zn}^{2+}$ concentration higher than 2 $\mathrm{mM}$ in the pNPP reaction (Fig. 4A).

AP-catalysed hydrolysis of pNPP is activated by both $\mathrm{Mg}^{2+}$ and $\mathrm{Zn}^{2+}$ ions in a way characteristic of synergistic interactions [15]. Since, optimal monoesterase activity of AP requires the interplay of both $\mathrm{Zn}^{2+}$ and $\mathrm{Mg}^{2+}$ ions, we compared the monoesterase and diesterase activities of CIAP in the presence of the two divalent metal ions (Fig. 5A and 5B). In agreement with earlier findings [14, 15], both metal ions are required for efficient monoester (pNPP) hydrolysis (Fig. 5A). However, the $\mathrm{Zn}^{2+}$-ion activated hydrolysis of bispNPP by CIAP was inhibited when increasing concentrations of $\mathrm{Mg}^{2+}$ ion were added to the reaction (Fig. 5B). $\mathrm{Zn}^{2+}$ ion is the preferred cofactor for the phosphodiesterase activity of CIAP, which is less dependent on $\mathrm{Mg}^{2+}$. Indeed, addition of $\mathrm{Mg}^{2+}$ specifically inhibited the hydrolysis of bispNPP.

\section{DISCUSSION}

Our finding in this study that the phosphomonoesterase activity of CIAP is more efficient than its phosphodiesterase activity reflects similar reports on ECAP [5]. Other

B

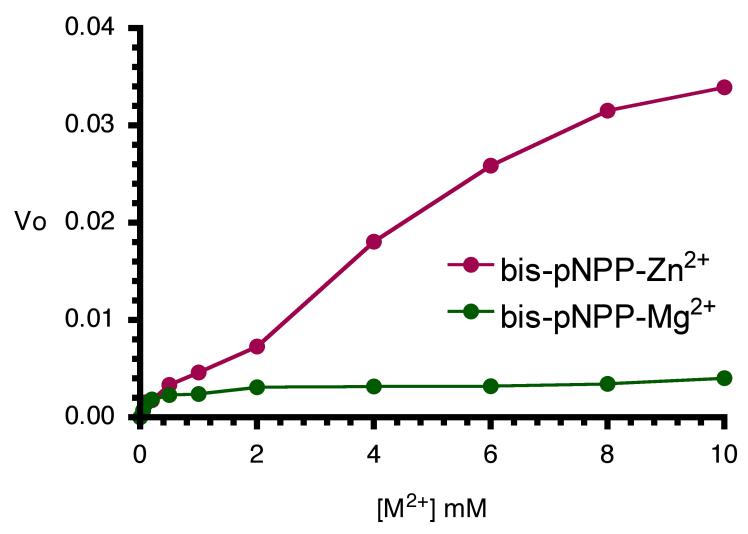

Fig. (4). Metal ion dependence of CIAP-catalysed hydrolysis of pNPP and bis-pNPP. Reaction mixtures (200 $\mu \mathrm{l})$ containing $25 \mathrm{mM}$ Tris$\mathrm{HCl}$ ( $\mathrm{pH} 8.5), 2.5 \mathrm{mM}$ p-nitrophenyl phosphate (A), or bis-p-nitrophenyl phosphate $(\mathbf{B})$, the indicated concentration of the metal ion $\left(\mathrm{ZnCl}_{2}\right.$ or $\mathrm{MgCl}_{2}$ ), and $10 \mu \mathrm{M} \mathrm{CIAP}$ were incubated at $37{ }^{\circ} \mathrm{C}$ for 10 minutes. Reactions were initiated by the addition of the substrate to the reaction mixture and stopped by the addition of $1.0 \mathrm{ml} 0.5 \mathrm{M} \mathrm{NaOH}$. Activities are expressed as change in $\mathrm{A}_{410}$ per minute for phosphomonoesterase activity and change in $\mathrm{A}_{410}$ per hour for the phosphodiesterase activity. 


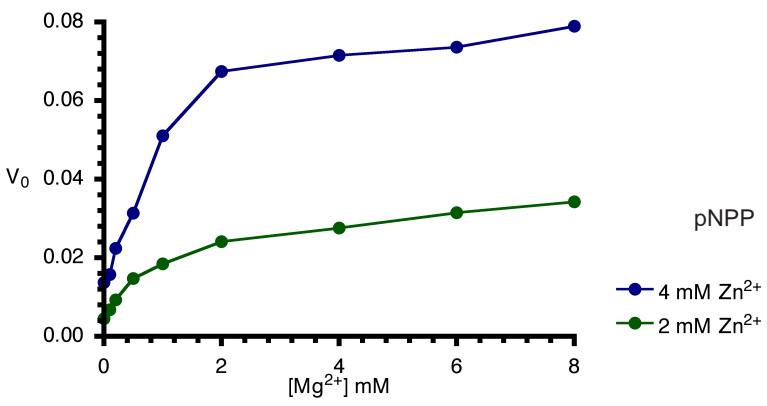

B

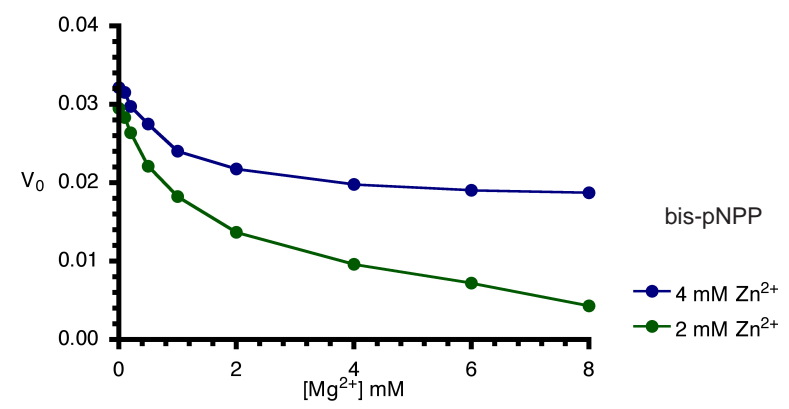

Fig. (5). Effects of $\mathrm{Mg}^{2+}$ on $\mathrm{Zn}^{2+}$-activated hydrolysis of pNPP and bis-pNPP by CIAP. Reaction mixtures (200 $\left.\mu 1\right)$ containing $25 \mathrm{mM}$ Tris$\mathrm{HCl}(\mathrm{pH} 8.5), 2.5 \mathrm{mM}$ p-nitrophenyl phosphate (A), or bis-p-nitrophenyl phosphate (B), $2 \mathrm{mM}$ or $4 \mathrm{mM} \mathrm{ZnCl}_{2}$ plus the indicated concentration of $\mathrm{MgCl}_{2}(0-10 \mathrm{mM})$, and $10 \mu \mathrm{M}$ CIAP were incubated at $37^{\circ} \mathrm{C}$ for 10 minutes. Reactions were initiated by the addition of the substrate to the reaction mixture and stopped by the addition of $1.0 \mathrm{ml} 0.5 \mathrm{M} \mathrm{NaOH}$. Activities are expressed as change in $\mathrm{A}_{410}$ per minute for phosphomonoesterase activity and change in $\mathrm{A}_{410}$ per hour for the phosphodiesterase activity.

mechanistic differences have been reported between the monoesterase and diesterase functionalities of ECAP. O'Brien et al., [17] reported that the R166S mutation in ECAP specifically inhibited monoesterase activity without affecting the hydrolysis of diester substrates, suggesting that the residue is important for binding and positioning of monoester substrates. The lack of effect of the R166S mutation on diester hydrolysis shows that this interaction does not contribute to the reaction of phosphate diesters, presumably because the introduction of steric bulk caused by esterification of a non-bridging oxygen of the transferred phosphoryl group prevents this interaction with the phosphate diester substrate [6].

Zalatan et al., [5] showed that removal of the $\mathrm{Mg}^{2+}$ site in ECAP had no significant effect on the diesterase reaction, while causing a significant decrease in monoesterase activity. Structural analysis and comparative studies with sulphate monoester substrates show that the R' group of diester substrates is oriented away from the $\mathrm{Mg}^{2+}$ site in AP (Fig. 2B). Hence, the active site $\mathrm{Mg}^{2+}$ has little or no contribution to rate acceleration of diester hydrolysis, in contrast to the monoesterase reaction that depends on $\mathrm{Mg}^{2+}$ in transition state stabilisation (Fig. 2A). It follows that catalysis of the diesterase reaction relies more on interactions with the bimetallocentre occupied by the two $\mathrm{Zn}^{2+}$ ions. This unique property of diesterase catalysis by AP might explain the inhibitory effect of $\mathrm{Mg}^{2+}$ if it displaces $\mathrm{Zn}^{2+}$ from the bimetallocentre [15]. In a comparative analysis of the hydrolysis of several diester substrates by ECAP-R166S, Nikolic-Hughes et al., [18] showed that rate enhancements correlated with the amount of negative charge localised between the two $\mathrm{Zn}^{2+}$ ions in the active site. Hence, the electrostatic features of the active site can be tuned to favour monoesterase or diesterase reactions when the coordinating properties of the bimetallocentres are altered. Such electrostatic contributions to the catalysis of diester hydrolysis by CIAP would be perturbed by the introduction of $\mathrm{Mg}^{2+}$ into one or both of the $\mathrm{Zn}^{2+}$ catalytic sites.

The synergistic effect of $\mathrm{Mg}^{2+}$ and $\mathrm{Zn}^{2+}$ in the activation of phosphomonoesterase activity of AP observed in this study confirmed our earlier report of the synergistic effects of $\mathrm{Zn}^{2+}$ and $\mathrm{Mg}^{2+}$ ions in the activation of TNAP [14, 15]. These and related findings $[19,20]$ suggest that the synergistic effect of the two cofactors is a recurrent theme of the two-metal ion mechanism of the alkaline phosphatases. However, the effect of interaction of $\mathrm{Mg}^{2+}$ and $\mathrm{Zn}^{2+}$ in the hydrolysis of bis-pNPP by CIAP as observed here did not show any synergistic effect though each metal ion in the absence of the other activates the enzyme. This would not be surprising if $\mathrm{Mg}^{2+}$ makes little contribution to rate enhancement of diester hydrolysis [5], in contrast to its significant impact in hydrolysis of phosphomonoester by alkaline phosphatase [15]. Activation of phosphodiesterase activity of CIAP by $\mathrm{Mg}^{2+}$ was limited, $\mathrm{Zn}^{2+}$ being the preferred metal ion for the hydrolysis of bis-pNPP. Interestingly, $\mathrm{Mg}^{2+}$ seems to displace $\mathrm{Zn}^{2+}$ from the enzyme and significantly inhibits the diesterase reaction. Keppetipola and Shuman [21] described mutants of a polynucleotide kinase/phosphatase from Clostridium temocellum with different cofactor requirements for its monoesterase and diesterase activities.

The alkaline phosphatase superfamily of hydrolase enzymes exhibits a high degree of substrate flexibility. This broad specificity means that the enzymes could be engineered to act with different affinities on a variety of phosphate esters. This can be achieved via random or directed mutagenesis of active site residues. The findings from this study offer the prospect of altering the substrate specificities of alkaline phosphatases and related bimetalloenzymes through changes in reaction cofactors in addition to efforts resulting from active site engineering.

\section{ACKNOWLEDGEMENTS}

We are grateful to Dr. Adrian Lapthorn (University of Glasgow) for generating Chemdraw formats of chemical structures; and Drs Sean Colloms and Louise Horsfall (University of Glasgow) for their helpful comments on the manuscript.

\section{CONFLICT OF INTEREST}

None declared.

\section{REFERENCES}

[1] Hoylaerts, M.F.; Manes, T.; Millan, J.L. Molecular mechanism of uncompetitive inhibition of human placental and germ cell alkaline phosphatase. Biochem. J., 1998, 286, 23-30. 
[2] Kim, E.E.; Wyckoff, H.W. Reaction mechanism of alkaline phosphatases based on crystal structures: Two-metal ion catalysis. J. Mol. Biol., 1991, 218, 449-464.

[3] Sowadski, J.M.; Handschumacher, M.D.; Murthy, H.M.K.; Foster, B.A.; Wyckoff, H.W. Refined structure of alkaline phosphatase from Escherichia coli at $2.8 \AA$ resolution. J. Mol. Biol., 1985, 186, 417-433.

[4] Bortolato, M.; Besson, F.; Roux, B. Role of metal ions on the secondary and quaternary structure of alkaline phosphatase from bovine intestinal mucosa. Proteins: Struct. Funct. Genet., 1999, 37, 310-318.

[5] Zalatan, J.G.; Fenn, T.D.; Hersclag, D. Comparative enzymology in the alkaline phosphatase superfamily to determine the catalytic role of an active site metal ion. J. Mol. Biol., 2008, 384, 1174-1189.

[6] O'Brien, P.J.; Herschlag, D. Functional interelationship in the alkaline phosphatase Superfamily: Phosphodiesterase Activity of Escherichia coli alkaline phosphatase. Biochemistry, 2001, 40, 5691-5699.

[7] Rezende, A.A.; Pizauro, J.M.; Ciancaglini, P.; Leone, F.A. Phosphodiesterase activity is a novel property of alkaline phosphatase from osseous plate. Biochem. J., 1994, 301, 517-522.

[8] Strater, N.; Lipscomb, W.N., Klabunde, T.; Krebs, B. Two-Metal Ion Catalysis in Enzymatic Acyl- and Phosphoryl-Transfer Reactions. Angew. Chem. Int. Ed., 1996, 35, 2024-2055.

[9] Wilcox, D.E. Binuclear metallohydrolases. Chem. Rev., 1996, 96, 2435- 2458.

[10] Zalatan, J.G.; Herschlag, D. Alkaline phosphatase mono- and diesterase reactions: comparative transition state analysis. J. Am. Chem. Soc., 2006, 128, 1293-1303.

[11] Millan, J.L. Alkaline phosphatases: Structure, substrate specificity and functional relatedness to other members of a large superfamily of enzymes. Purinergic Signal., 2006, 2, 335-341.

[12] Le Du, M.H.; Stigbrand, T.; Taussig, M.J.; Menez, A.; Stura, E.A. Crystal structure of alkaline phosphatase from human placenta at 1.8 A resolution. Implication for a substrate specificity. J. Biol. Chem., 2001, 276, 9158-9165.

[13] Petitclerc, C.; Fecteau, C. Mechanism of action of $\mathrm{Zn}^{2+}$ and $\mathrm{Mg}^{2+}$ on rat placental alkaline phosphatases II. Studies on membrane bound phosphatase in tissue sections and in whole placenta. Can. $J$. Biochem., 1977, 55, 474-478.

[14] Arise, R.O.; Bolaji, F.F.; Jimoh, O.A.; Adebayo, J.O.; Olorunniji, F.J.; Malomo, S.O. Regulatory effect of divalent cations on rat liver alkaline phosphatase activity: How $\mathrm{Mg}^{2+}$ activates (and inhibits) the hydrolysis of p-nitrophenylphosphate. Biokemistri, 2005, 17, 129136.

[15] Olorunniji, F.J.; Igunnu, A.; Adebayo, J.O.; Arise, R.O.; Malomo, S.O. Cofactor interaction in the activation of tissue non-specific Alkaline phosphatase: Synergistic effects of $\mathrm{Zn}^{2+}$ and $\mathrm{Mg}^{2+}$ ions. Biokemistri, 2007, 19, 43-48.

[16] Gijsbers, B.; Ceulemans, H.; Stalmans, W.; Bollen, M. Structural and catalytic similarities between nucleotide pyrophosphatases/phosphodiesterases and alkaline phosphatase. $J$. Biol. Chem., 2001, 276, 1361-1368.

[17] O’Brien, P.J.; Lassila, K.J.; Fenn, T.D.; Zalatan, J.G.; Herschlag, D. Arginine coordination in enzymatic phosphoryl transfer: Evaluation of the effect of Arg166 mutations in Escherichia coli alkaline phosphatase. Biochemistry, 2008, 47, 7663-7672.

[18] Nikolic-Hughes, I.; O'Brien, P.J.; Herschlag, D. Alkaline phosphatase catalysis is ultrasensitive to charge sequestered between the active site zinc ions. J. Am. Chem. Soc., 2010, 127, 9314-9315.

[19] Sorimachi, K. Activation of alkaline phosphatase with $\mathrm{Mg}^{2+}$ and $\mathrm{Zn}^{2+}$ in rat hepatoma cells. J. Biol. Chem., 1987, 262, 1535-1541.

[20] Koutsioulis, D.; Lyskowski, A.; Maki, S.; Guthrie, E.; Feller, G.; Bouriotis, V.; Heikinheimo, P. Coordination sphere of the third metal site is essential to the activity and metal selectivity of alkaline phosphatases. Protein Sci., 2010, 19, 75-84.

[21] Keppetipola, N.; Shuman, S. Distinct enzymic functional groups are required for the phosphomonoesterase and phosphodiesterase activities of Clostridium thermocellum polynucleotide kinase/phosphatase. J. Biol. Chem., 2006, 281, 19251-19259.

[22] DeLano, W.L. (2002) The PyMOL Molecular Graphics System. DeLano Scientific, San Carlos, CA, USA. http://www.pymol.org.

(C) Igunnu et al.; Licensee Bentham Open .

This is an open access article licensed under the terms of the Creative Commons Attribution Non-Commercial License (http://creativecommons.org/licenses/by-nc/3.0/) which permits unrestricted, non-commercial use, distribution and reproduction in any medium, provided the work is properly cited. 